\title{
In-silico Strategies of Some Selected Phytoconstituents from Zingiber officinale as SARS CoV-2 Main Protease (COVID-19) Inhibitors
}

\author{
DSNBK Prasanth', Siva Prasad Panda ${ }^{1,2}$, Atmakuri Lakshmana Rao ${ }^{3}$, Guntupalli Chakravarti ${ }^{1}$, Nayudu \\ $\mathrm{Teja}^{4}$, Veenam Bhavya Naga Vani ${ }^{3}$, Tera Sandhya ${ }^{5}$
}

${ }^{1}$ Pharmacognosy Research Division, K L College of Pharmacy, Koneru Lakshmaiah Education Foundation, Vaddeswaram, Guntur, Andhra Pradesh, INDIA.

${ }^{2}$ Pharmacology Research Division, K L College of Pharmacy, Koneru Lakshmaiah Education Foundation, Vaddeswaram, Guntur, Andhra Pradesh, INDIA.

${ }^{3}$ Department of Pharmaceutical Analysis, V. V. Institute of Pharmaceutical Sciences, Gudlavalleru, Andhra Pradesh, INDIA. ${ }^{4}$ Department of Pharmaceutics, V. V. Institute of Pharmaceutical Sciences, Gudlavalleru, Andhra Pradesh, INDIA.

${ }^{5}$ Department of Pharmacology, Institute of Pharmaceutical technology, Sri Padmavati Manila Visvavidyalayam, Tirupati, Andhra Pradesh, INDIA.

\begin{abstract}
Background: Zingiber officinale (Zingiberaceae) has been utilized to remedy many afflictions of humans. Literary works illustrate that it possesses numerous biological activities. Methods: Today, research study intended to recognize the Phyto-derived antiviral substances from Zingiber officinale against COVID-19 main protease enzyme and to understand the molecular basis of its activity. Methods: In the present study, 42 molecules obtained from $Z$. officinale, which are retrieved from the Pubmed database, are studied via docking study. Docking study was performed using Autodock vina and PyRx software. Afterwards, admet SAR, as well as Dru Li to servers, were made use of for drug-likeness prophecy. Results: Our study shows that the nine phytochemicals of $Z$. officinale are very likely against the main protease enzyme of COVID-19. Utilizing contemporary strategies, these phyto-compounds might use to establish a reliable medication from a natural origin. Conclusion: The substances identified potential as possible anti-virals. However, even more, in-vitro studies are needed to examine their effectiveness versus COVID-19.
\end{abstract}

Key words: Zingiber officinale, ADMET, PyRx, Physico-chemical, PASS analysis.

\section{INTRODUCTION}

WHO has currently stated a typical emergency situation and also pandemic for the coronavirus (COVID-19) that has proactively propagating around the entire world. The virus SARS-CoV-2 can easily trigger signs and symptoms such as high temperature, coughing, pneumonia, queasiness, as well as exhaustion. ${ }^{1}$ The epidemiological history of the infection was actually believed to derive from a seafood market in Wuhan, China. Having said that, the exact origin of the preliminary transmission to human beings is actually still unidentified. Presently, there is actually $>100$ total genome patterns recognized in the NCBI GenBank, coming from over ten nations. The variant in between these series is actually much less than $1 \%$.The SARS$\mathrm{CoV}-2$ has been identified as $\beta$-coronavirus causes severe respiratory tract infection in humans and utilize angiotensin-converting enzyme 2 (ACE2) receptors to infect humans. ${ }^{3}$ Chinese experts separated SARS$\mathrm{CoV}-2$ and also sequenced the genome SARS-CoV2 on January 7, 2020. ${ }^{4}$ The crystallized kind of COVID-19 primary protease $\left(\mathrm{M}_{\mathrm{pro}}\right)$ was actually displayed through a Chinese scientist Liu et cetera (2020) that it is actually a possible medication aim at target protein for the inhibition of
Submission Date: 13-05-20; Revision Date: 07-07-2020; Accepted Date: 13-08-20

DOI: 10.5530/ijper.54.3s.154 Correspondence: Dr. D S N B K Prasanth Associate Professor, Department of

Pharmacognosy, K L College of Pharmacy, Koneru Lakshmaiah Education Foundation, Vaddeswaram -522 502, Guntur, Andhra Pradesh, INDIA. Phone: +917382027437 E-mail: dsnbkprasanth@ kluniversity.in

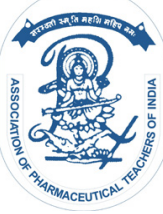

www.ijper.org 
SARS-CoV-2 replication. The $\mathrm{M}_{\text {pro }}$ is an essential protein required for the proteolytic maturation of the virus. ${ }^{5}$ Thus, targeting $\mathrm{M}_{\text {pro }}$ has the potential to provide effective treatment against SARS-CoV-2 by inhibition of the viral polypeptide cleavage. The spike protein of virus binds to the tissues membrane layer with a receptor-mediated communication which enables a way to the host cell and also this makes it possible for the application of the well-known protein designs to rapidly develop a version for medicine break through on this brand-new SARS-CoV-2. ${ }^{6}$ While standard procedures of medicine finding might take years, the strategy taken right here to look for available medicines for the SARS-COV-2 resides in silico docking styles coming from proteins in the SARS-CoV-2, the spike glycoprotein, as well as the SARS-CoV-2 main protease. In-silico based testing has confirmed to be a handy tool t to satisfy the obstacles of anti-viral medication invention. Variety of natural or synthetic substance collections through computational assessment strategies as docking conserves information in terms of money as well as time. ${ }^{7}$ Natural compounds have served humans as cheaper and safer drug candidates against several diseases and historically been beneficial to human health since the dawn of medicine. ${ }^{8-10}$ Thus, we have screened a small library of natural compounds against $\mathrm{M}_{\text {pro }}$ by in silico based screening. In the present research, we have chosen ginger, which is a potent source of anti-viral agents. ${ }^{11-13}$ Zingiber officinale (Zingiberaceae) is a traditional Indian medicine used for hundreds of year to relieve various lung-related disorders includes pneumonia, infectious disease, as well as malignant pleural effusion. ${ }^{14,15}$ Recently, several studies also provided scientific data to support and unveil its antioxidant, antimicrobial, anti-diabetic, anticancer, anti-inflammatory, analgesic, antipyretic, immune-modulator, anti-obesity, hepatoprotective, anti-angiogenic, larvicidal, anthelmintic, neuroprotective, gastroprotective and cardiovascular activity.

\section{MATERIALS AND METHODS Data Source}

A list of active phytochemicals was acquired from Indian Medicinal Plants, Phytochemistry and Therapeutic Data Base. ${ }^{16,17}$

\section{Docking Studies \\ Preparation of Protein}

The protein's atomic coordinates, COVID-19 (PDB ID: 6LU7), were retrieved from the RCSB PDB site. The charge assignment, solvation parameters and fragmental volumes to the protein were performed using Autodock Tool 4 (ADT) before study or docking. The protein molecule was further designed for molecular docking ${ }^{18}$ (Figure 1).

\section{Preparation of ligands and analysis of drug likeliness}

The crystal 3D structure of 42 active compounds from ginger including Aframodial (PubChem CID-9905088), [6]-Paradol (PubChem CID- 94378), [6]-Shogaol (PubChem CID- 5281794), beta-Cadinene (PubChem CID-10657), Cedr-8-ene (PubChem CID- 6431015), Copaene (PubChem CID- 12303902 ), Gingerenone-A (PubChem CID- 5281775), Isogingerenone B (PubChem CID- 5318568 ), Shogasulfonic acid A (PubChem CID10388428) and Zonarene (PubChem CID- 6428488 ) were retrieved from PubChem dabase. ${ }^{19}$ Drug-likeliness properties of ligands were analyzed for the selected active compounds using DruLiTo software ${ }^{20}$ (Figure 2).
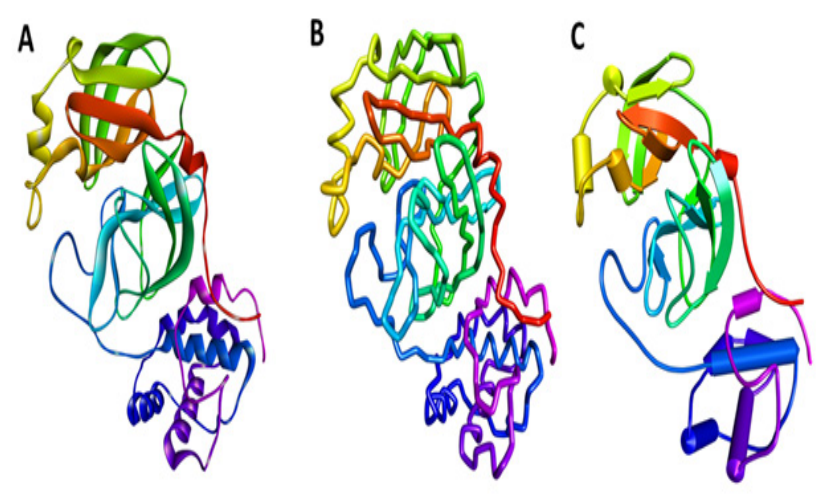

Figure 1: Three Dimensional Crystal Structure of the molecular target, COVID-19 main protease (6LU7) was represented in (A) Solid ribbon (B) Tube (C) Schematic.

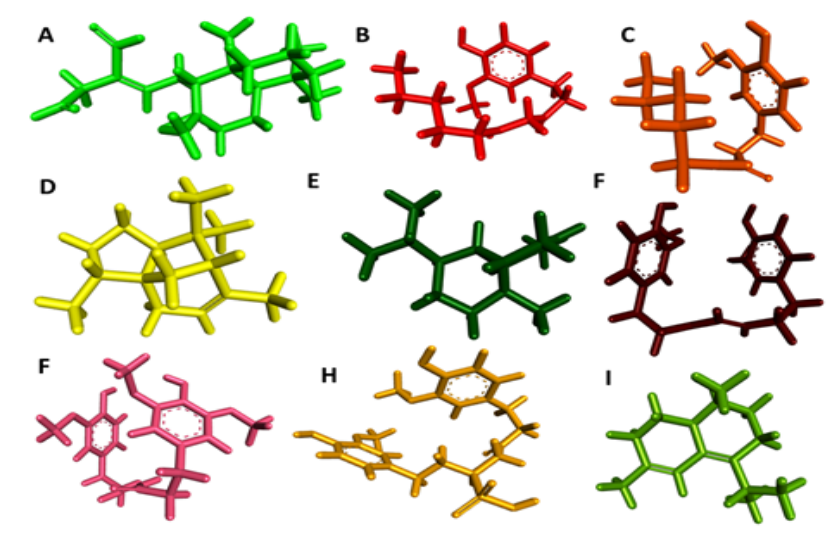

Figure 2: The Three Dimensional structures of ligands. (A) Aframodial (B) [6]-Paradol (C) [6]-Shogaol (D) Cedr-8-ene (E) Copaene (F) Gingerenone-A (G) Isogingerenone- $B(H)$ Shogasulfonic acid A (I) Zonarene. 


\section{Compound screening using PyRx program}

The auto-dock wizard was used as docking engine to molecular check all compound libraries with PyRxoftware. ${ }^{21}$ The ligands were found versatile during the do process, and and the protein should be rigid. The grid parameter configuration file was created with $\mathrm{PyRx}$ Auto Grid motor. In the test, the amino acids in the active protein site reacting with the nds have werebeen known/prd. The tests tests e root-middlemean-square deviation (RMSD) of less than $1.0 \AA$ were deemed optimal and grouped together to determine the desirable relation. The lowest (most negative) binding energy was recognized as the most binding ligand.

\section{Analysis and visualization}

Visual examination of the docking site was performed using Biovia Drug discoverdio 2019, and and the results were validated using AodockVina. ${ }^{22}$

\section{ADMET Analysis}

ADMET of the ligands is their pharmacokinetic properties that are required to be examined to establish their function inside the body. The ADMET inheritance of the ligands was studied, making use of aet SAR. ${ }^{23,24}$

\section{PASS computer Program}

Prophecy of Zingiber officinale for anti-viral activity was created with the assistance of software, PASS. PASS is a computer system based program utilized for the prognosis of various sorts of physiological actions for multiple compounds consisting of phytoconstituents. The estimated activity of a substance is predicted as probable activity $(\mathrm{Pa})$ and probable inactivity $(\mathrm{Pi})$. The substances revealing $\mathrm{Pa}$ higher than $\mathrm{Pi}$ are actually the only components thought about as feasible for a specific medical activity. ${ }^{25-27}$

\section{RESULTS}

\section{Drug likeliness Properties}

The physicochemical properties of the chosen nine active compounds were studied on DruLi to software. All the compounds obeyed Lipinski's rule (Table 1). Shogasulphonic acid A, gingerenone B shows higher TPSA (138.74, 85.22) and AMR (61.16, 61.4) with suitable HBA, HBD and RB (Table 1). TPSA, as well as AMR, are fundamental physicochemical properties mostly entailed in drug absorption, transport and penetratn mechanism. ${ }^{28}$

\section{Molecular Docking Studies}

To discover a prospective candidate for COVID19, molecular docking work was carried out on 42 phytoconstituents acquired from Z. Officinal binding pocket COVID-19 (PDB ID: 6LU7). These 42 substances were docked towards the COVID-19 target enzyme and rated based on their dock performance. Compounds with a dock value of -6.0 or less are deemed a great example for COVID-19 control. For a detailed review, refer to Table 2. This table displays the number of active molecules acquired after docking. These active molecules have a dock value of -6.0 or lower. Total of 10 compounds was chosen based on 6LU7 binding interactions. Shogasulphonic acid A demonstrated the best-docked score $(-6.9 \mathrm{Kcal} / \mathrm{mol})$ with SARS-CoV2 Main Proteases.

\section{Molecular Interaction Studies}

The rigid docking results were envisioned utilizing Discovery studio for evaluation of communications. The best binding postures of protein-ligand communications were envisioned and charted eThe most st + rongstrongest connection was noticed in the Shogasulphonic acid A with main protease protein

\begin{tabular}{|c|c|c|c|c|c|c|c|c|c|c|c|}
\hline \multicolumn{3}{|c|}{ Table 1: Physicochemical properties of the active compounds and accordance with the rules of drug-likeness. } \\
$\begin{array}{c}\text { Sr. } \\
\text { No. }\end{array}$ & Ligand & MW & logp & Alogp & HBA & HBD & TPSA & AMR & nRB & $\begin{array}{c}\text { No. of } \\
\text { MR }\end{array}$ \\
\hline 1 & [6]-Paradol & 292.17 & 3.247 & -1.686 & 2 & 1 & 63.6 & 53.72 & 10 & 83.59 & 0 \\
\hline 2 & [6]-Shogaol & 276.17 & 4.225 & -0.875 & 1 & 1 & 46.53 & 53.97 & 9 & 82.91 & 0 \\
\hline 3 & Aframodial & 318.22 & 5.062 & 0.926 & 3 & 0 & 46.67 & 90.38 & 5 & 92.44 & 0 \\
\hline 4 & Cedr-8-ene & 204.19 & 6.597 & 2.484 & 0 & 0 & 0 & 65.35 & 0 & 66.88 & 0 \\
\hline 5 & Copaene & 204.19 & 6.499 & 1.763 & 0 & 0 & 0 & 64.85 & 1 & 67.14 & 0 \\
\hline 6 & Gingerenone-A & 356.16 & 3.321 & -0.512 & 1 & 2 & 75.99 & 54.08 & 9 & 101.49 & 0 \\
\hline 7 & Isogingerenone B & 386.17 & 2.877 & -0.564 & 1 & 2 & 85.22 & 61.4 & 10 & 107.98 & 0 \\
\hline 8 & $\begin{array}{c}\text { Shogasulfonic } \\
\text { acid A }\end{array}$ & 438.13 & 1.417 & -1.974 & 4 & 3 & 138.74 & 61.16 & 11 & 112.5 & 0 \\
\hline 9 & Zonarene & 204.19 & 5.643 & 2.299 & 0 & 0 & 0 & 67.49 & 1 & 69.04 & 0 \\
\hline
\end{tabular}




\section{Table 2: Molecular docking of selected compounds} with Main Protease target proteins.

\begin{tabular}{|c|c|c|}
\hline \multirow{2}{*}{ Sr. No } & \multirow{2}{*}{ Ligands } & Dock Score (Kcal/mol) \\
\cline { 3 - 3 } & & $\mathbf{6 L U 7}$ \\
\hline 1 & $(+)-$-Cyclosativene & -5.8 \\
\hline 2 & $(-)-$ Camphor & -4.6 \\
\hline
\end{tabular}

\begin{tabular}{|c|c|c|}
\hline 2 & $(-)-$ Camphor & -4.6 \\
\hline 3 & $(-)$-Germacrene_D & -5.9 \\
\hline 4 & $(-)-$ Zingiberene & -5 \\
\hline 5 & (E)-Nerolidol & -4.8 \\
\hline
\end{tabular}

\begin{tabular}{|c|c|c|}
\hline 6 & (E, E)-alpha-Farnesene & -4.8 \\
\hline 7 & (S)-6-Gingerol. & -5.9 \\
\hline 8 & (S)-6-Gingerol & -4.9 \\
\hline
\end{tabular}

\begin{tabular}{|c|c|c|}
\hline 9 & $1,8-C i n e o l e$ & -4.9 \\
\hline 10 & 1-Dehydro-[10]-gingerdione & -5.5 \\
\hline 11 & 10-Shogaol & -5.3 \\
\hline
\end{tabular}

\begin{tabular}{|c|c|c|}
\hline 11 & 10-Shogaol & -4.8 \\
\hline 12 & 2-Nonanone & -5.1 \\
\hline 13 & 3-Carene & -5.1 \\
\hline 14 & 4(10)-Thujene & -4.5 \\
\hline
\end{tabular}

\begin{tabular}{|l|c|c|}
\hline 14 & $4(10)-$ Thujene & -4.5 \\
\hline 15 & 4 -Terpineol & -4.6 \\
\hline 16 & Aframodial & -5.9 \\
\hline 17 & Borneol & -4.6 \\
\hline 18 & Cedr-8-ene & -6.2 \\
\hline
\end{tabular}

\begin{tabular}{|c|c|c|}
\hline 18 & Cedr-8-ene & -6.2 \\
\hline 19 & Citronellol & -4.5 \\
\hline 20 & Copaene & -6 \\
\hline 21 & Geraniol & -4.5 \\
\hline
\end{tabular}

\begin{tabular}{|c|c|c|}
\hline 21 & Geraniol & -4.5 \\
\hline 22 & Gingerenone_A & -6.5 \\
\hline 23 & Isogingerenone_B & -6.4 \\
\hline 24 & Nerol & -4.9 \\
\hline 25 & Nonanol & -3.8 \\
\hline 26 & Safrole & -5.1 \\
\hline
\end{tabular}

\begin{tabular}{|c|c|c|}
\hline 26 & Sesquithujene & -5.1 \\
\hline 28 & Shogasulfonic_acid_A & -6.9 \\
\hline 29 & Terpinolene & -4.9 \\
\hline 30 & Zingiberenol. & -5.4 \\
\hline 31 & Zingiberenol & -5.4 \\
\hline 32 & Zonarene & -6.3 \\
\hline 33 & [6]-Gingerdione & -5.7 \\
\hline 34 & [6]-Paradol & -6.1 \\
\hline 35 & [6]-Shogaol & -6 \\
\hline 36 & [7]-Paradol & -5.5 \\
\hline 37 & alpha-Muurolene & -5.7 \\
\hline 38 & alpha-Pinene & -4.8 \\
\hline 39 & beta-Bisabolene & -5.6 \\
\hline 40 & beta-Cadinene & -5.8 \\
\hline 41 & beta-Santalol & -5.3 \\
\hline 42 & beta-Sesquiphellandrene & -5.4 \\
\hline
\end{tabular}

complexes. The main protease with shogasulphonic acid A complex formed six hydrogen bond, i.e., ARG A:105; $6.34 \mathrm{~A}^{\circ}$, GLN A:107; $4.08 \mathrm{~A}^{\circ}$, GLN A:110; $3.43 \mathrm{~A}^{\circ}$, $5.02 \mathrm{~A}^{\circ}$, THR A:111; $3.39 \mathrm{~A}^{\circ}$, ASP A:295; $3.97 \mathrm{~A}^{\circ}$, one pi sigma interaction, i.e., ILE A:106; $5.39 \mathrm{~A}^{\circ}$ and one pi alkyl interactions, i.e., VAL A:104; $6.03 \mathrm{~A}^{\circ}$ (Figures 3-6 and Table 3).

Except for Cedr-8-ene, Copaene and Zonarene, remaining all ligands are involved in hydrogen bond formation with protein. In this view, majorly two primary amino acids are mainly engaged in the hydrogen bond interactions, i.e., GLN A:107 A and THR A:111 A .

All the ligands are involved in the hydrophobic interactions with the protein. Majorly two primary amino acids are mainly engaged in the hydrophobic bond interacti i.e., VAL A:104: A $^{\circ}$ and PHE A:294: 294 $A^{\circ}$. No ligand forms electrostatic interactions with the protein.

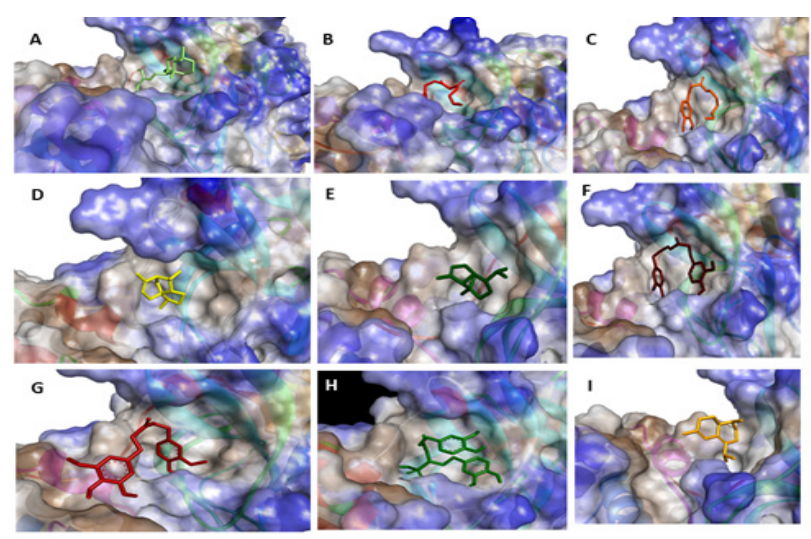

Figure 3: In silico Docked complexes of Ligand (Ball and Stick representation) with COVID-19 main protease (6LU7) (Molecular representation) by Biovia Drug Discovery Studio 2019. (A) Aframodial (B) [6]-Paradol (C) [6]-Shogaol (D) Cedr8-ene (E) Copaene (F) Gingerenone-A (G) Isogingerenone-B (H) Shogasulfonic acid A (I) Zonarene.

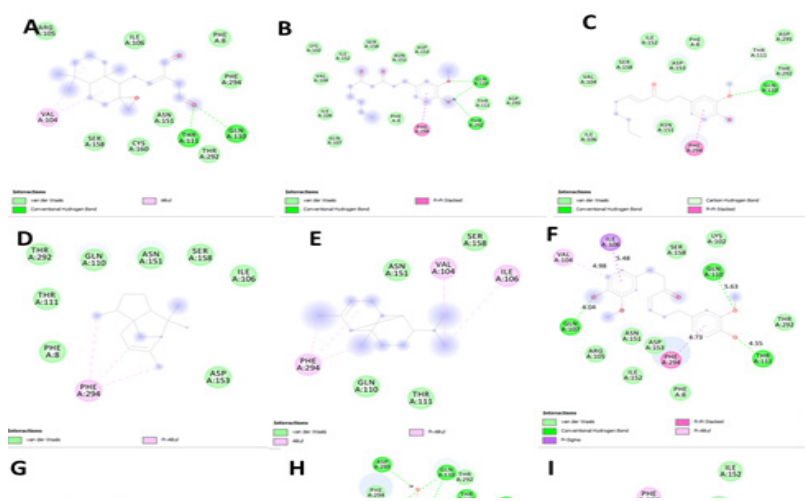

Figure 4: Various Two-dimensional Interactions of ligands with COVID-19 main protease (6LU7). (A) Aframodial (B)

[6]-Paradol (C) [6]-Shogaol (D) Cedr-8-ene (E) Copaene (F) Gingerenone-A (G) Isogingerenone-B $(H)$ Shogasulfonic acid A (I) Zonarene. 
照

D

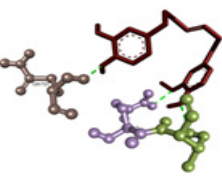

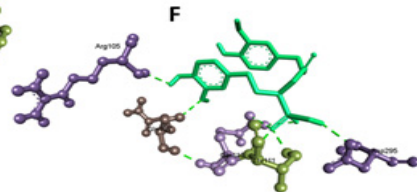

Figure 5: Various three-dimensional Interactions of ligands with COVID-19 main protease (6LU7) via Hydrogen Bond (A) Aframodial (B) [6]-Paradol (C) [6]-Shogaol (D) Gingerenone-A (E) Isogingerenone-B (F) Shogasulfonic acid A.

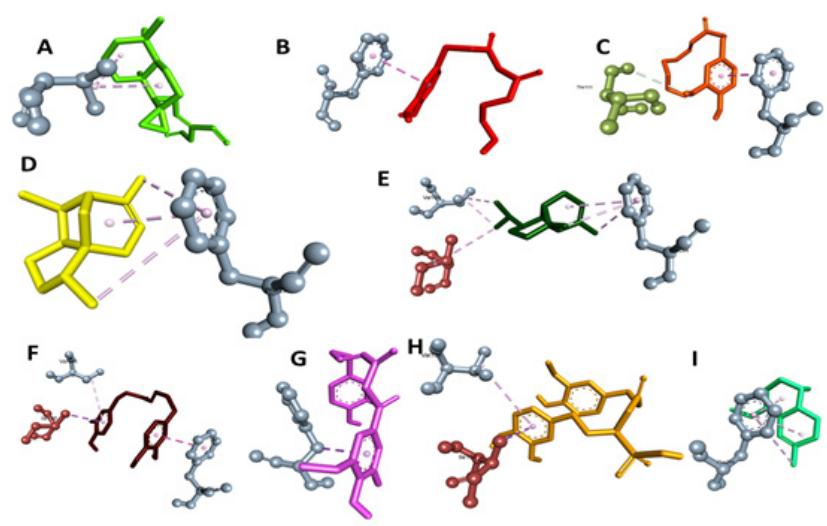

Figure 6: Various three-dimensional Interactions of ligands with COVID-19 main protease (6LU7) via Hydrophobic Interactions. (A) Aframodial (B) [6]-Paradol (C) [6]-Shogaol

(D) Cedr-8-ene (E) Copaene (F) Gingerenone-A (G) Isogingerenone-B (H) Shogasulfonic acid A (I) Zonarene.

\section{ADME/T evaluation by using admet SAR}

The ADMET properties of the ligands were assessed, making use of admet SAR. ADMET properties for the substances in the research study were evaluated, making use of admet SAR. All the substances revealed excellent human intestinal absorption (HIA), blood-brain barrier (BBB) infiltration. No medication was cancer-causing. All the compounds were AMES negative. The results of $\mathrm{HIA}, \mathrm{BBB}, \mathrm{LD}_{50}$ values for the compounds are listed in Table 4.

\section{PASS predictions for anti-viral activity}

The biological activity spectra of previously identified phytoconstituents were obtained by online PASS version. These predictions were interpreted and used in a flexible manner and given in Table 5. 6-Paradol, 6-shagaol, cedr8 -ene, gingerenone- $\mathrm{A}$, Isogingerenone- $\mathrm{B}$ and Zonarene showed values $\mathrm{Pa}>\mathrm{Pi}$ against various viruses.

\section{DISCUSSION}

CoronavirusesCorona viruses have a long history of infecting humans and animals and causing respiratory, digestive, liver and central nervous system disses in them. ${ }^{29}$ A novel newly emerged SARS-CoV-2 is presenting major threats health noways nowadays. ${ }^{30}$ The primary focus has been on clinical management which includes the prevention of infection, control measures and supportive care. Currently, no specific clinical therapeutics are available for the treatment of SARSCoV-2-medied infections. ${ }^{31}$ Thus, the need of the hour

\begin{tabular}{|c|c|c|c|}
\hline \multirow{2}{*}{ Ligands } & \multirow{2}{*}{$\begin{array}{c}\text { Binding Affinity, } \\
\Delta G \text { (Kcal/mol) }\end{array}$} & \multicolumn{2}{|c|}{ Amino acids involved and Distance $\left(A^{\circ}\right)$} \\
\hline & & Hydrogen Binding Interactions & Hydrophobic Interactions \\
\hline Aframodial & -6.1 & THR A:111 (3.45), GLN A:110 (3.79) & VAL A:104 (5.62. 5.63) \\
\hline [6]-Paradol & -6.1 & $\begin{array}{c}\text { GLN A:110 }(4.27,5.53), \text { THR A:292 } \\
(3.62)\end{array}$ & PHE A:294 (4.84) \\
\hline [6]-Shogaol & -6 & GLN A:110 (4.34) & THR A:111 (3.83). PHE A:294 (4.88) \\
\hline Cedr-8-ene & -6.2 & - & PHE A:294 (5.16; 521; 5.45) \\
\hline Copaene & -6 & - & $\begin{array}{c}\text { VAL A:104 }(4.50,4.67), \text { ILE A:106 (5.17),PHE } \\
\text { A:294 }(4.09,4.60,6.20)\end{array}$ \\
\hline Gingerenone-A & -6.5 & $\begin{array}{c}\text { GLN A: } 107 \text { (4.04), GLN A:110 (3.79), } \\
\text { THR A:111 (4.55) }\end{array}$ & $\begin{array}{c}\text { VAL A:104 (4.98), ILE A:106 (5.48), PHE A:294 } \\
\text { (4.73), }\end{array}$ \\
\hline Isogingerenone-B & -6.4 & $\begin{array}{c}\text { THR A:111 (3.36;3.52), GLN A:110 } \\
(3.81)\end{array}$ & PHE A:294 (4.35) \\
\hline Shogasulfonic acid $\mathrm{A}$ & -6.9 & $\begin{array}{c}\text { ARG A:105 (6.34), GLN A:107 } \\
\text { (4.08), GLN A:110 (3.43, 5.02), THR } \\
\text { A:111 (3.39), ASP A:295 (3.97) }\end{array}$ & VAL A:104 (6.03),ILE A:106 (5.39) \\
\hline Zonarene & -6.3 & - & PHE A: 294 (4.69, 4.75, 4.90, 5.54) \\
\hline
\end{tabular}


is to identify and characterize novel drug candidate to overcome the health loses caused by SARS-CoV-2.

With this new breakthrough of Mpro structure in COVID-19, it has offered an astounding possibility to recognize the prospective drug candidates for the effective therapy of coronavirus. In this context, natural products have gained importance as potent anti-viral agents duri rent years. ${ }^{32,33}$ Considering the immediate need of therapeutics against COVID-19 and services of natural products in drug discovery, we have screened phytoconstituents from $Z$. officinaleas novel drug molecules against Mpro, of SARS-CoV-2 for the identification of Mpro inhibitors to provide natural scaffolds for drug development.

Our examination majorly concentrated on exploring for nutraceutical valuable novelconstituents from the herbal plant of Z. officinale with suited pharmacological efficiency and minimum toxicity against COVID-19. From this result, the nine selected phytoconstituents from $Z$. officinale is specifically chosen for further study.

Out of 42 candidates, nine compounds displayed a higher binding affinity with least binding energy with the main protease enzyme. Shogasulphonic acid A has a least binding energy of $-6.9 \mathrm{Kcal} / \mathrm{mol}$ and found to make six hydrogen bonds with five amino acids, i.e., ARG A:105 (6.34), GLN A:107 (4.08), GLN A:110 (3.43, 5.02), THR A:111 (3.39), ASP A:295 (3.97) and one hydrophobic interaction with PHE A:294 (4.35).ept with, ARG A:105: 105 , remaining, the bond length of hydrogen bonds is $<5$ $\mathrm{A}^{\circ}$, which indicaonding is stronger more substantialand formed stable complexes. Whereas, Gingerenone A has a binding energy of $-6.5 \mathrm{kcal} / \mathrm{mol}$, associates with three hydrogen bonds with GLN A: 107 (4.04), GLN A:110 (3.79), THR A:111 (4.55) and hydrophobic interactions with VAL A:104 (4.98), ILE A:106 (5.48), PHE A:294 (4.73). These two compounds have the least binding affinity in comparison with other ligands due to the formation of more hydrogen bonds with the proteins. All the ligands are involved in hydrophobic interactions; mainly, twacids were involvedined, i.e., PHE A:294: 294, VAL A:104 and ILE A:106.

Lipinski's five-rule is a primary standard for assessing drug likeliness. Lipinski's law specifies the molecular properties essential to the pharmacokinetics of medication in the human bs ADME. Lipi 'sLipinski's law rule of five cond optimal medicationmedicines. Three or more breaches do not meet with the drug likeliness requirements and are not considered to continue product exploration. ADME analyses of selected nine compounds show that all met these ADME check screens (Table 3). This preliminary screening of possible molecules (anti-virals) will help to provide rapid in-silico analysis for SARSCoV2 (COVID-19) therapy production.

Thus, we anticipate that the consumption of Z. officinale has the potential to boost immunity to fight against COVID-19 infections.

\section{CONCLUSION}

In this research study, we have actually made use of Bioinformatics resources, PyRx and also AutodockVina to identify the potent molecules from $Z$. officinale against COVID-19 Main Proteases, which participate in a vital part in Coronavirus propagation. Our results propose that the nine phytoconstituents which include [6]-Paradol,[6]-Shogaol, Cedr-8-ene, Copaene, Gingerenone A, Isogingerenone B, Shogasulfonic acid A and Zonarenebe made use of as potential inhibitors of COVID-19 Main Proteases, which may be additionally discovered to examine against Coronavirus (COVID19) in in-vitro, pre-clinical and also clinical tria

\section{ACKNOWLEDGEMENT}

The authors, thanks to the Management of K L College of Pharmacy, Vaddeswaram, Guntur (Dt.), Andhra Pradesh for providing the research facilities.

\section{CONFLICT OF INTEREST}

The authors declare no conflict of interest

\section{ABBREVIATIONS}

Mpro: Main Protease; Z. officinale: Zingiberofficinale; SARSCoV-2: Severe acute respiratory syndrome coronavirus 2; NCBI: National Center for Biotechnology Information; ACE2: Angiotensin-converting enzyme; PDB: Protein DataBase; DruLiTo: Drug Likeliness Tool; PASS: Prediction of Activity Spectra for Substances; TPSA: topological polar surface area; AMR: Atom Molar Refractivity; HBA: Hydrogen bond acceptor; HBD: Hydrogen bond donor; BBB: BloodBrain Barrier; HIA: human intestinal absorption; $\mathbf{L D}_{50}$ : Lethal Dose, $50 \%$.

\section{REFERENCES}

1. Organization WH. Coronavirus disease 2019 (COVID-19). Situation Report. 2020.

2. Chen N, Zhou M, Dong X, Qu J, Gong F, Han Y, et al. Epidemiological and clinical characteristics of 99 cases of 2019 novel coronavirus pneumonia in Wuhan, China: A descriptive study. Lancet. 2020;395(10223):507-13. doi:10.1016/S0140-6736(20)30211-7.

3. Li Q, Guan X, Wu P, Wang X, Zhou L, Tong Y, et al. Early transmission dynamics in Wuhan, China, of novel coronavirus-infected pneumonia. New England Journal of Medicine. 2020 
4. Lu R, Zhao X, Li J, Niu P, Yang B, Wu H, et al. Genomic characterization and epidemiology of 2019 novel coronavirus: Implications for virus origins and receptor binding. Lancet. 2020;395(10224):565-74. doi:10.1016/S01406736(20)30251-8.

5. Jin Z, Du X, Xu Y, Deng $\mathrm{Y}$, Liu M, Zhao $\mathrm{Y}$, et al. Structure of Mpro from COVID-19 virus and discovery of its inhibitors. Bio Rxiv. 2020.

6. Hui DS, Azhar El, Madani TA, Ntoumi F, Kock R, Dar O, et al. The continuing 2019-nCoV epidemic threat of novel coronaviruses to global health-The latest 2019 novel coronavirus outbreak in Wuhan, China. International Journal of Infectious Diseases. 2020;91:264.

7. Murgueitio MS, Bermudez M, Mortier J, Wolber G. In silico virtual screening approaches for anti-viral drug discovery. Drug Discov Today Technol. 2012;9(3):e219-25. doi:10.1016/j.ddtec.2012.07.009.

8. Castro T, Barbosa K, Albarello N, Figueiredo S. Caracterização de pseudofrutos, frutos, sementes e plântulas obtidas a partir de germinação in vivo and in vitro da espécie medicinal Hovenia dulcis (Rhamnaceae). Revista Cubana de Plantas Medicinales. 2005;10:1-16.

9. Shen B. A New Golden Age of Natural Products Drug Discovery. Cell. 2015;163(6):1297-300. doi:10.1016/j.cell.2015.11.031.

10. Thomford NE, Senthebane DA, Rowe A, Munro D, Seele P, Maroyi A, et al. Natural Products for Drug Discovery in the $21^{\text {st }}$ Century: Innovations for Novel Drug Discovery. Int J Mol Sci. 2018;19(6):1578. doi:10.3390/ijms19061578.

11. Rastogi S, Pandey DN, Singh RH. COVID-19 pandemic: A pragmatic plan for ayurveda intervention. J Ayurveda Integr Med. 2020. doi:https://doi. org/10.1016/j.jaim.2020.04.002.

12. Panyod S, Ho CT, Sheen LY. Dietary therapy and herbal medicine for COVID-19 prevention: A review and perspective. Journal of Traditional and Complementary Medicine. 2020. doi:https://doi.org/10.1016/j. jtcme.2020.05.004.

13. Cao P, Wu S, Wu T, Deng $\mathrm{Y}$, Zhang $\mathrm{Q}$, Wang $\mathrm{K}$, et al. The important role of polysaccharides from a traditional Chinese medicine-Lung Cleansing and Detoxifying Decoction against the COVID-19 pandemic. Carbohydrate Polymers. 2020;240:116346. doi:https://doi.org/10.1016/j. carbpol.2020.116346.

14. Townsend EA, Siviski ME, Zhang Y, Xu C, Hoonjan B, Emala CW. Effects of ginger and its constituents on airway smooth muscle relaxation and calcium regulation. Am J Respir Cell Mol Biol. 2013;48(2):157-63. doi:10.1165/ rcmb.2012-02310C.

15. Lai K, Shen H, Zhou X, Qiu Z, Cai S, Huang K, et al. Clinical Practice Guidelines for Diagnosis and Management of Cough-Chinese Thoracic Society (CTS) Asthma Consortium. J Thorac Dis. 2018;10(11):6314-51. doi:10.21037/jtd.2018.09.153.

16. Mohanraj K, Karthikeyan BS, Vivek-Ananth R, Chand RB, Aparna S, Mangalapandi $\mathrm{P}$, et al. IMPACT: A curated database of Indian Medicinal Plants, Phytochemistry and Therapeutics. Scientific Reports. 2018;8(1):1-17

17. Chaudhuri S, Symons JA, Deval J. Innovation and trends in the development and approval of anti-viral medicines: 1987-2017 and beyond. Anti-viral Research. 2018;155:76-88.
18. Morris GM, Huey R, Lindstrom W, Sanner MF, Belew RK, Goodsell DS, et al. AutoDock 4 and AutoDock Tools 4: Automated docking with selective receptor flexibility. J Comput Chem. 2009;30(16):2785-91. doi:10.1002/jcc.21256.

19. O'Boyle NM, Banck M, James CA, Morley C, Vandermeersch T, Hutchison GR. Open Babel: An open chemical toolbox. J Cheminform. 2011;3(1):33. doi:10.1186/1758-2946-3-33.

20. Pangastuti A, Amin IF, Amin AZ, Amin M. Natural bioactive compound from Moringa oleifera against cancer based on in silico screening. Jurnal Teknologi. 2016;78(5).

21. Dallakyan S, Olson AJ. Small-molecule library screening by docking with PyRx. Chemical biology: Springer. 2015;243-50.

22. Seeliger D, DeGroot BL. Ligand docking and binding site analysis with PyMOL and Autodock/Vina. J Comput Aided Mol Des. 2010;24(5):417-22. doi:10.1007/s10822-010-9352-6.

23. Yang H, Lou C, Sun L, Li J, Cai Y, Wang Z, et al. admetSAR 2.0: Web-service for prediction and optimization of chemical ADMET properties. Bioinformatics. 2019;35(6):1067-9. doi:10.1093/bioinformatics/bty707.

24. Cheng F, Li W, Zhou Y, Shen J, Wu Z, Liu G, et al. Admet SAR: A comprehensive source and free tool for assessment of chemical ADMET properties. ACS Publications. 2012.

25. Khurana N, Ishar MP, Gajbhiye A, Goel RK. PASS assisted prediction and pharmacological evaluation of novel nicotinic analogs for nootropic activity in mice. Eur J Pharmacol. 2011;662(1-3):22-30. doi:10.1016/j. ejphar.2011.04.048.

26. Mittal M, Goel RK, Bhargava G, Mahajan MP. PASS-assisted exploration of antidepressant activity of 1,3 , 4-trisubstituted- $\beta$-lactam derivatives. Bioorganic and Medicinal Chemistry Letters. 2008;18(20):5347-9.

27. Goel RK, Singh D, Lagunin A, Poroikov V. PASS-assisted exploration of new therapeutic potential of natural products. Med Chem Res. 2011;20(9):150914.

28. Ertl P, Rohde B, Selzer P. Fast calculation of molecular polar surface area as a sum of fragment-based contributions and its application to the prediction of drug transport properties. Journal of Medicinal Chemistry. 2000;43(20):37147.

29. To KK, Hung IF, Chan JF, Yuen KY. From SARS coronavirus to novel animal and human coronaviruses. J Thorac Dis. 2013;5 (Suppl 2):S103-8. doi:10.3978/j.issn.2072-1439.2013.06.02.

30. Zhu N, Zhang D, Wang W, Li X, Yang B, Song J, et al. A Novel Coronavirus from Patients with Pneumonia in China, 2019. N Engl J Med. 2020;382(8):72733. doi:10.1056/NEJMoa2001017.

31. Zhou Y, Hou Y, Shen J, Huang Y, Martin W, Cheng F. Network-based drug repurposing for novel coronavirus 2019-nCoV/SARS-CoV-2. Cell Discov. 2020;6(1):14. doi:10.1038/s41421-020-0153-3.

32. Lin LT, Hsu WC, Lin CC. Anti-viral natural products and herbal medicines. J Tradit Complement Med. 2014;4(1):24-35. doi:10.4103/2225-4110.124335.

33. Martinez JP, Sasse F, Bronstrup M, Diez J, Meyerhans A. Anti-viral drug discovery: Broad-spectrum drugs from nature. Nat Prod Rep. 2015;32(1):2948. doi:10.1039/c4np00085d.

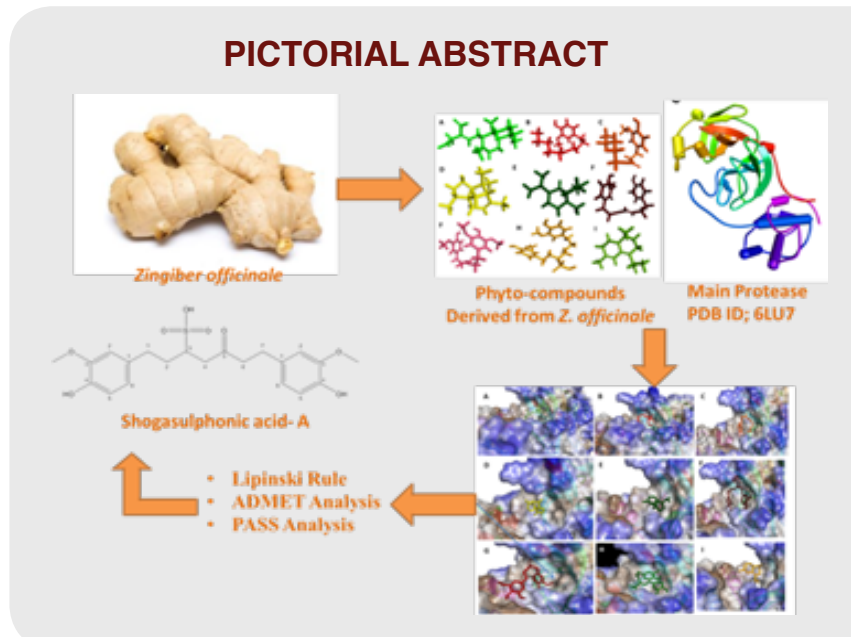

\section{SUMMARY}

- $\quad$ Current coronavirus disease (COVID-19) pandemic worldwide is synonymous with 'Severe acute respiratory syndrome' (SARS-CoV2) in humans.

- In this context, the phytoconstituents from Z. officinale were screened against the Main Protease,

- Based on the binding energy levels, nine phytocompounds has been chosen and out of all Shogasulphonic acid displayed the lowest binding energy of $-6.9 \mathrm{Kcal} / \mathrm{mol}$.

- All the compounds obeyed Lipinski's rule and none of them is carcinogenic in nature. 


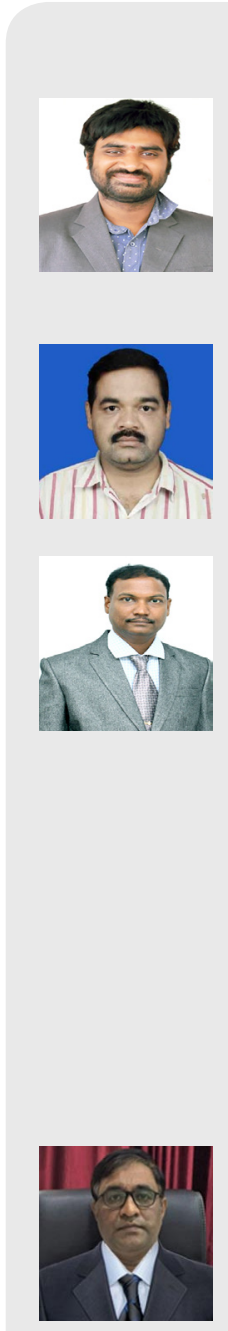

Dr. D. S. N. B. K. Prasanth is working as an Associate Professor at K L College of Pharmacy, Koneru Lakshmaiah Education Foundation, Vaddeswaram, Guntur, Andhra Pradesh, INDIA. He is having 8 years of Teaching and Research experience. He guiding 3 Ph.D. Scholars and 20 B. Pharm Candidates. He published 28 papers in various International and National Journals. He is Reviewer and Editorial Board Member for some reputed International and National journals. He is having memberships in 02 professional societies.

Dr. Siva Prasad Panda is working as an Associate Professor at K L College of Pharmacy, Koneru Lakshmaiah Education Foundation, Vaddeswaram, Guntur, Andhra Pradesh, INDIA. He is having 15 years of Teaching and Research experience. He guiding 5 Ph.D. Scholars and 35 B. Pharm Candidates. He published 20 papers in various International and National Journals. He is Reviewer and Editorial Board Member for some reputed International and National journals.

Dr. A. Lakshmana Rao is working as a Professor and Principal of V. V. Institute of Pharmaceutical Sciences, Gudlavalleru, A.P. He is having 20 years of Teaching, Research and Administrative experience. He guided 9 Ph.D. Scholars and 58 M.Pharm. Candidates. He received many awards and prizes from various organizations. He received Dr.APJ Abdul Kalam Award for Teaching Excellence from Marina Labs, Chennai; Noble Principal of the Year Award from Operant Pharmacy Federation, Rajasthan and Principal of the Year Award from Association of Pharmacy Professionals, Bhopal. He conferred with Meritorious University Best Teacher Award from Jawaharlal Nehru Technological University Kakinada, Kakinada. He is given 10 Guest Lectures in different universities and colleges. He published 302 papers in various International and National Journals. He published 1 Text Book and 2 E-Books. He is Editor-in-Chief, Reviewer and Editorial Board Member for 111 reputed International and National journals. He organized 25 Seminars, Conferences and Workshops. He participated 89 Seminars, Conferences and Workshops. He presented 32 scientific papers in various Seminars and Conferences and received 12 prizes. He is having 1 Indian Patent in his credit. He received Grants from $\mathrm{AICTE}$ and $\mathrm{PCl}$. $\mathrm{He}$ is having memberships in various professional societies like IPA, APTI, ABAP, APP, ISTE etc.

Dr. Chakravarthi: Guntupalli working as Professor and Principal, K L College of Pharmacy, K L University. He is a highly motivated, analytical and dedicated individual with hands-on laboratory experience within Pharmaceutics fields supported by a strong academic background and methodologies combined with the ability to work productively in a multidisciplinary environment. He worked as a research scholar in the University of Sunderland UK, over 5 years of research and 15 years of teaching experience. Ph.D. in Phytochemical analysis (U.K) Master of pharmacy in Pharmacognosy (B.I.T RANCHI). For his credit he has 15 international publications in various international peer reviewed journals and he attended 5 international and 5 national conferences

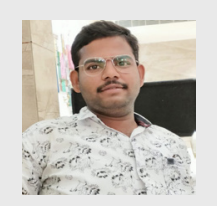

Mr. Nayudu Teja, is currently pursuing M. Pharm of Pharmaceutics at V. V. Institute of Pharmaceutical Sciences, Seshadri Rao Knowledge Village, Gudlavalleru, Andhra Pradesh, INDIA.

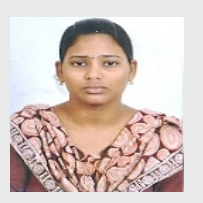

Ms. Veenam Bhavya Naga Vani, is currently pursuing M. Pharm of Pharmaceutical Analysis at V. V. Institute of Pharmaceutical Sciences, Seshadri Rao Knowledge Village, Gudlavalleru, Andhra Pradesh, INDIA

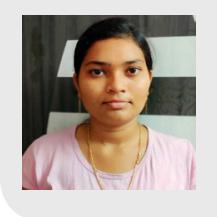

Ms. Tera Sandhya, is currently pursuing M. Pharm of Pharmacology at Institute of Pharmaceutical technology, Sri Padmavati Manila Visvavidyalayam, Tirupati, Andhra Pradesh, INDIA.

Cite this article: Prasanth DSNBK, Panda SP, Rao AL, Chakravarti G, Teja N, Vani VBN, et al. In-silico Strategies of Some Selected Phytoconstituents from Zingiber officinale as SARS CoV-2 Main Protease (COVID-19) Inhibitors. Indian J of Pharmaceutical Education and Research. 2020;54(3s):s552-s559. 